\section{TNM staging and T-cell receptor gamma expression in colon adenocarcinoma. Correlation with disease progression?}

\author{
Francesca Castiglione ${ }^{1}$, Antonio Taddei ${ }^{2}$, Anna Maria Buccoliero', \\ Francesca Garbini ${ }^{1}$, Chiara Francesca Gheri ${ }^{1}$, Giancarlo Freschi ${ }^{2}$, Paolo Bechi ${ }^{2}$, \\ Duccio Rossi Degl'Innocenti ${ }^{1}$, and Gian Luigi Taddei ${ }^{1}$ \\ ${ }^{1}$ Department of Human Pathology and Oncology, ${ }^{2}$ Department of Surgical Pathology, \\ University of Florence, School of Medicine, Florence, Italy
}

ABSTRACT

Aims and background. Colorectal cancer is the second most common cause of cancer-related death in Europe and the United States. Several studies have evaluated the immune response to colorectal cancer, with contradictory results. Some studies showed that lymphocyte infiltration in colorectal cancer seemed to be an important prognostic parameter, a finding not confirmed by other studies. Several studies showed the gamma-delta T-cell receptor repertoire of intestinal adenocarcinoma. In this study, we hypothesize that the presence of $\mathrm{T}$ cells with the T-cell receptor gamma complex may play a particular role in carcinogenesis and tumor progression.

Methods. A total of 58 patients with colon adenocarcinoma was included in the analysis. We used the TNM staging system to grade colon cancer.

Results. Thirty samples $(52.6 \%)$ revealed a polyclonal rearrangement of T-cell receptor gamma. In the N0 cases, only 5 samples revealed a T-cell receptor gamma molecular assessment; in $\mathrm{N} 1 / \mathrm{N} 2$ cases, 25 revealed a T-cell receptor gamma molecular assessment.

Conclusions. The results showed statistical significance between the presence of Tcell receptor gamma and N1/N2 stage lymph nodes $(P=0.001)$.

\section{Introduction}

Colorectal cancer is the second most common cause of cancer-related death in Europe and the United States. It is calculated that more than 350,000 new cases are diagnosed and, in Europe, approximately 200,000 patients die from this disease every year ${ }^{1}$. Mortality rates for colon cancer have decreased during the past 10-15 years, due to the early detection, the more effective screening programs, and because of the adjuvant and neoadjuvant chemotherapeutic treatments that have led to a significant increase in tumor response and median survivall ${ }^{1,2}$.

Several studies have evaluated the immune response to colorectal cancer ${ }^{3-5}$. Results of these studies are contradictory. Some studies have shown that lymphocyte infiltration in colorectal cancer seems to be an important prognostic parameter, but other studies did not confirm such findings ${ }^{3-5}$.

Intraepithelial lymphocytes are T cells that reside between the epithelial cells and a distinct cellular compartment. T cells can express different types of the T-cell receptor (TCR). The TCR is a heterodimeric receptor that can be formed from two different pairs of chains: the alpha and beta chains (alpha/beta TCR) or the gamma and delta chains (gamma/delta TCR). In humans, $5-15 \%$ of the intraepithelial cells in the small bowel and up to $40 \%$ in the colon express the gamma/delta $\mathrm{TCR}^{5-9}$.

Several studies have shown the gamma-delta TCR repertoire of intestinal adenocarcinoma. They found that most of these $\mathrm{T}$ cells rearrange the variable region $\mathrm{V}_{\%_{0}} 1$ and
Key words: colon adenocarcinoma, immune host response, TCR-gamma.

Correspondence to: Francesca Castiglione, Department of Human Pathology and Oncology, University of Florence, School of Medicine, Viale GB Morgagni 85, 50134 Florence, Italy. Tel +39-055-4478121;

fax +39-055-4379868;

e-mail francesca.castiglione@unifi.it

Received June 7, 2007; accepted September 7, 2007 
display two distinct features ${ }^{3-5}$. The first feature is that their TCR repertoire is highly restricted and stable over time. Thus, despite the theoretical potential for generating an enormous number of different TCR transcripts, a remarkably restricted repertoire is found within the intestinal $\mathrm{T}$ cells. The second feature is that highly compartmentalized $\mathrm{T}$ cells, expressing distinct TCR transcripts, were found within different parts of the intestine or the peripheral blood. These findings imply a function that involves local activity of the cell against a narrow repertoire of ligands. This important function of the mucosal gamma-delta T-cell population is not completely known ${ }^{10-12}$.

These $\mathrm{T}$ cells play an important role in maintaining host cell integrity. TCR-gamma expression in tumor-infiltrating lymphocytes is significantly lower than in normal tissue, suggesting T-cell localization in colon tumors. Even though tumor cells express antigens that are capable of activating a host immune response, colon cancers still develop. It has been suggested that an inadequate T-cell response may in part be responsible for this phenomenon. Colon cancer cell lines can also produce factors that, in turn, inhibit Tcell function ${ }^{5-9}$.

In the present study, we hypothesized that the presence of T cells with a TCR gamma complex may play a particular role in carcinogenesis and tumor progression.

\section{Patients and methods}

\section{Case selection}

We selected tissue blocks of intestinal colon adenocarcinoma from the archives of the Department of Human Pathology and Oncology of the University of Florence. The specimens were obtained from 58 patients with known follow-up, all of whom underwent surgical radical colon resection at the Department of Surgical Pathology of the University of Florence from 2002 to 2003. Any suspected lesions are examined with macroscopic and microscopic evaluation. Thirty-three patients were males and 25 were females, ranging in age from 88 to 40 years (mean, 55). Informed consent was obtained from every patient prior to surgery, and tumor samples were collected during surgery. All the specimens were analyzed by the same pathologist, and patients were divided according to the TNM classification. We compared a group of patients according to TNM N0 (Figure 1) to a series of patient N1 and N2 of the pathology (Figure 2) and evaluated the presence/absence of gamma-delta TCR in intestinal adenocarcinoma.

\section{DNA extraction and genetic analysis of TCR gamma}

DNA was isolated from formalin-fixed, paraffin-embedded tissue sections. After dewaxing and proteinase $\mathrm{K}$ digestion, the DNA was heated to $96^{\circ} \mathrm{C}$ for $10 \mathrm{~min}$ to

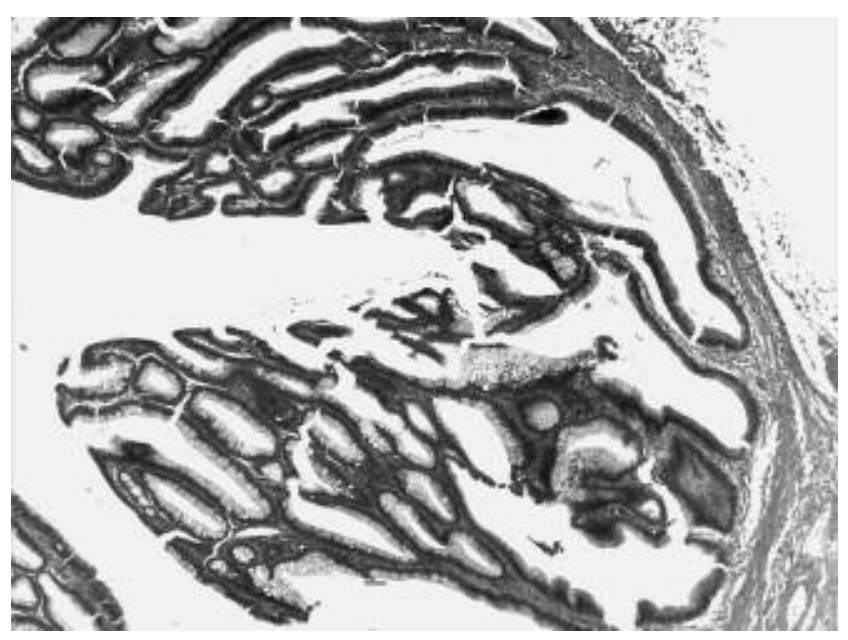

Figure 1 - Colon adenocarcinoma (hematoxylin-eosin. x10). The figure shows a moderately well-differentiated, infiltrating adenocarcinoma of the colon.

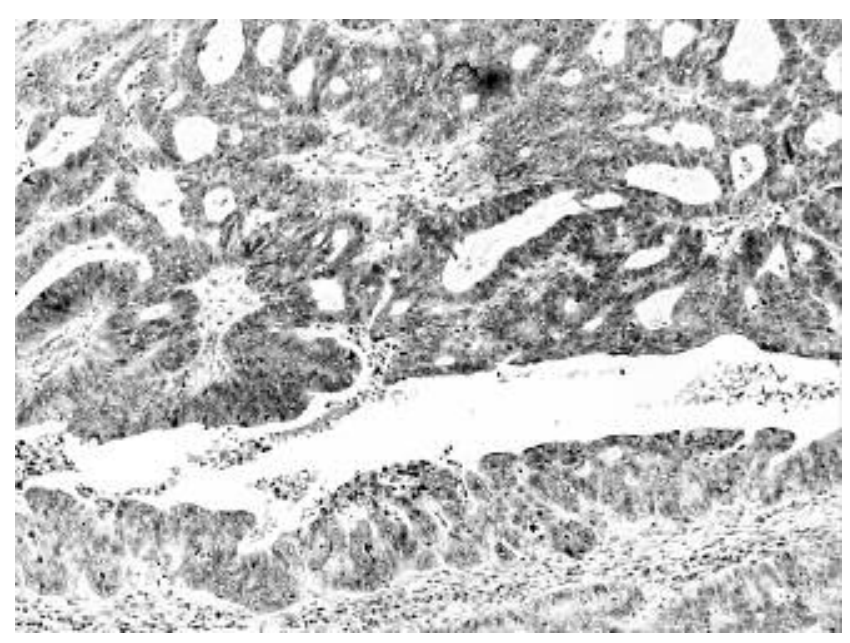

Figure 2 - Colon adenocarcinoma (hematoxylin-eosin, x10). The figure shows an undifferentiated, infiltrating adenocarcinoma of the colon with irregulars glands.

destroy proteinase Kactivity. The DNA was extracted using the "GenomicPrep Cells and Tissue DNA Isolation Kit" (GE Healthcare, Buckinghamshire, UK) according to the manufacturer's protocol. DNAs were quantified by spectrophotometry and the DNA fragmentation state was evaluated by $2 \%$ agarose gel.

The polymerase chain reaction (PCR) assay for TCR $\gamma$ rearrangement was performed with the consensus primers TV $\gamma$ (5'-AGGGTTGTGTTGGAATCAGG-3') and TJ $\gamma$ (5'- CGTCGACAACAAGTGTTGTTCCAC -3'). The assay is a two-step PCR. The first reactions were carried out in a volume of $20 \mu \mathrm{l}$, with $1.5 \mathrm{mM} \mathrm{MgCl}_{2}, 0.125 \mathrm{mM}$ dNTPs, 2 pmol of TJ $\gamma$ primer and 1 U Taq polymerase 
(Applied Biosystems, Foster City, CA, USA) with 200-350 ng of DNA template. The cycle conditions were: $15 \mathrm{~s}$ at $94^{\circ} \mathrm{C}, 20 \mathrm{~s}$ at $58^{\circ} \mathrm{C}$ and $20 \mathrm{~s}$ at $72^{\circ} \mathrm{C}$ for 25 cycles.

Later on, $20 \mu \mathrm{l}$ of fresh PCR reagents were added to products of first amplification, at concentrations of 1.5 $\mathrm{mM} \mathrm{MgCl}_{2}, 0.375 \mathrm{mM}$ dNTPs, $12 \mathrm{pmol}$ of TJ $\gamma$ primer, 18 pmol of TV $\gamma$ primer and $1 \mathrm{U}$ Taq polymerase. The cycles of this second amplification were 31 with the same parameters of the previous reaction.

PCR products were analyzed by $15 \%$ acrylamide gel electrophoresis and visualized under UV illumination after ethidium bromide staining. A broad smear can be obtained from a sample with infiltration of polyclonal reactive $\mathrm{T}$ cell. Instead, a discrete band suggests the presence of a monoclonal T-lymphocyte proliferation. A PCR not showing smears or bands after polyacrylamide gel electrophoresis means the tissue does not contain $\mathrm{T}$ lymphocytes.

\section{Statistical analysis}

The presence of TCR gamma/delta T cells in the two groups of colon carcinoma (correlated with disease progression) was calculated according to the Wilcoxon Mann-Whitney test. Data analysis was performed using SPSS Version 11.0 (SPSS, Chicago, IL, USA) statistical package. Fisher's exact test was applied to statistical analysis of amplification's return. A $P$ value $\leq 0.05$ was considered to be statistically significant.

\section{Results}

Overall, 58 patients with colon adenocarcinoma were included in the analysis. We used the TNM staging system to grade the colon cancer. There were 33 N0 patients, $13 \mathrm{~N} 1$ patients and $12 \mathrm{~N} 2$ patients. We compared the 33 patients with N0 to the 25 patients with N1/N2 cancers. The molecular rearrangement of TCR gamma was evaluated. In all cases, DNA extraction was successful and the DNA fragmentation state was low. Thirty samples $(52.6 \%)$ revealed a polyclonal rearrangement of TCR gamma (Figure 3). In the N0cases, only 5 samples revealed a TCR gamma polyclonal rearrangement; in the N1/N2 cases, 25 revealed a TCR gamma polyclonal rearrangement (Figure 4). These results show statistical significance between the presence of TCR gamma and N1/N2 stage lymph nodes $(P=0.001)$. However, there was no significant correlation between the presence of TCR gamma, tumor extension and the presence of metastasis $(P=0.06)$.

\section{Discussion}

Changes in cell surface receptor expression in gastrointestinal mucosa may play a role in the pathogene-

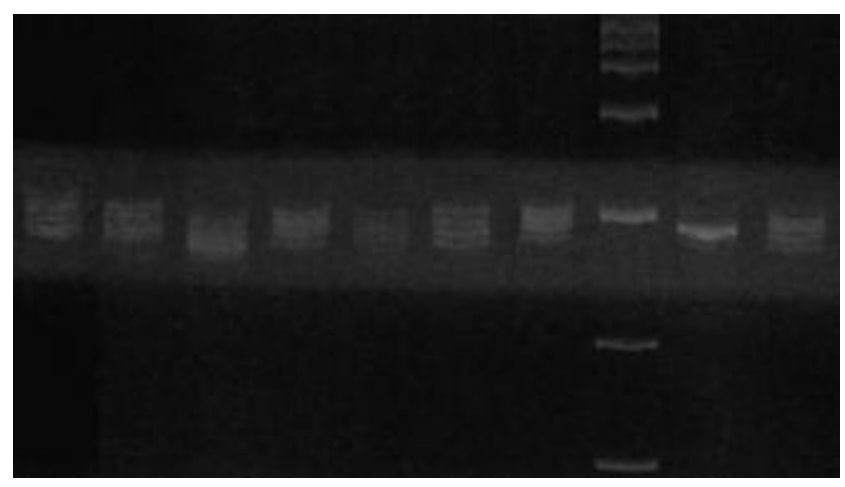

Figure 3 - Ethidium bromide-stained polyacrylamide gel of PCR products from colon adenocarcinoma (lanes 1-7), monoclonal control (cutaneous T cell lymphoma) (lane 9) and polyclonal control (lichen planus) (lane 10). The DNA marker is shown in lane 8.

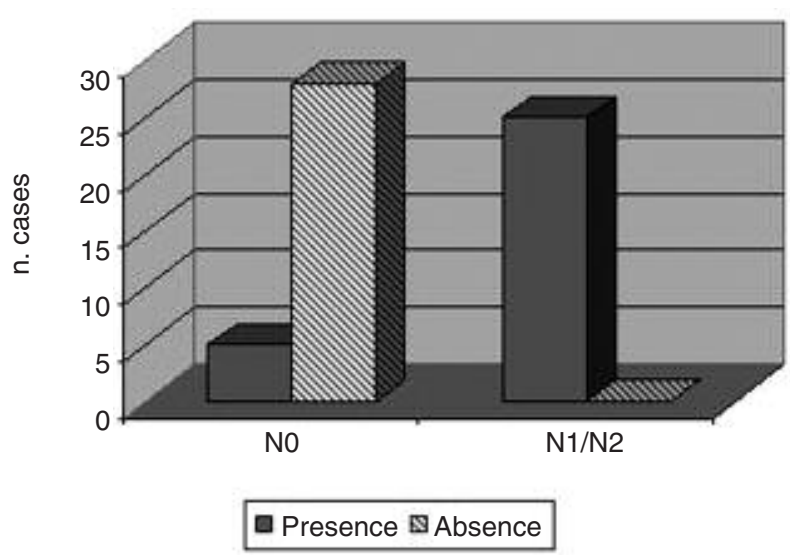

Figure 4 - The graph shows TCR-gamma presence in the different disease stages. Five N0 cases (16\%) and 25 N1/N2 cases $(97 \%)$ showed TCR-gamma expression.

sis of colon cancer. Activation of $\mathrm{T}$ lymphocytes is initiated by binding of the TCR antigen (antigen: OK???). TCR is a multimeric protein complex consisting of a disulfide-linked gamma/delta heterodimer that is noncovalently associated with the CD3 polypeptidic chains. Whereas the alpha and beta proteins contain all of the information necessary for antigen recognition, the CD3 molecules are responsible for signal transduction. The immunoglobulin-like gamma chain, along with the delta chain, is expressed at the surface of a subset of $\mathrm{T}$ lymphocytes ${ }^{13-15}$.

Two different chain combinations of the TCR complex are used for antigen recognition: TCR alpha/beta and TCR gamma/delta. Gamma/delta cells share numerous features with their alpha and beta counterparts but they have several unique properties. Gamma and delta $\mathrm{T}$ cells are more prominent in the skin and gastrointestinal mucosa than in peripheral blood and conventional 
lymphoid organs. These $\mathrm{T}$ cells play an important role in maintaining host cell integrity. TCR-gamma expression in tumor-infiltrating lymphocytes is significantly higher than in normal intestinal tissue, suggesting $\mathrm{T}$ cell localization in colon tumors ${ }^{16-18}$.

Even though tumor cells express antigens that are capable of activating a host immune response, colon cancers still develop. It has been suggested that an inadequate T-cell response may in part be responsible for this feature. Colon cancer cells can also produce factors that modulate T-cell function. TCR-gamma/delta cells are selectively and consistently localized in colon tumor tissue $^{19,20}$.

We evaluated the expression of TCR gamma in 58 patients with colon adenocarcinoma. The patients were divided into two groups based on TNM stage: the first group included N0 patients and the second group N1/N2 patients. We detected TCR gamma in 30 cases (53\%). Twenty-one cases were N1 and 4 N2, and only 5 cases were N0. We observed that the presence of gam$\mathrm{ma} /$ delta T-cells was significantly correlated with disease progression $(P=0.001)$. In addition, our study confirmed that intratumor TCR has a prognostic role in advanced colon carcinoma.

We found a significant correlation between the presence of TCR gamma and N1/N2 positive lymph nodes $(P=0.001)$. The characterization of tumor-specific antigens showed that tumors may have antigen determinants which are recognized by the immune system. A recent study indicated that these antigens may be tumor-specific peptides that are absent in all adult normal tissues except germline cells. Immunotherapy using adoptive cell transfer is a promising approach which can result in the regression of bulky invasive cancer in some patients.

As regards colon cancer, some studies have reported that some colon carcinoma specimens showed a leukocyte infiltrate. In addition, tumor-associated lymphocytes with polyclonal expansion were demonstrated in colon cancer cell lines. In colon cancer patients, it seems that the clinical outcome may depend on tumor characteristics (stage of disease, residual disease, histologic type and grade of differentiation) and on the host response to cancer. The manipulation of immune mechanisms may offer powerful therapeutic tools for the treatment of colon cancer patients. In recent years, several studies have focused on the possible use of $\mathrm{T}$ cells to attack established tumors ${ }^{21,22}$.

In the present study, we observed a significant correlation between the presence of TCR gamma and disease in N1/N2-positive lymph nodes (53\%), whereas N0 patients $(47 \%)$ did not show gamma/delta $\mathrm{T}$ cells $(P=$ 0.001). This finding (which we have evaluated for the first time in the literature) suggests the presence of TCR gamma may have a determinant prognostic role in colon adenocarcinoma treatment. TCR gamma expression is associated with an advanced stage of the pathol- ogy. A recent study showed that gamma/delta T cells, involved in inflammatory responses, play a central role in tissue damage.

Further studies are necessary to better understand the negative prognostic role of gamma/delta $\mathrm{T}$ cells in colon carcinoma. Nevertheless, these data emphasize the importance of the immune host response to cancer and the need to better study the immune mechanisms in order to modulate therapeutic treatment of cancer.

\section{References}

1. International Agency for Research on Cancer (IARC): Pathology and Genetics of Tumours of the Digestive System. In: World Health Organization Classification of Tumors, Kleihues P, Sobin LH (Eds), pp. 105-106, IARC press, Lyon, 2000.

2. Sheehan KM, O'Connell F, O'Grady A, Conroy RM, Leader MB, Byrne MF, Murray FE, Kay EW: The relationship between cyclooxygenase-2 expression and characteristics of malignant transformation in human colorectal adenomas. Eur J Gastroenterol Hepatol, 16: 619-625, 2004.

3. Naito Y, Saito K, Shiiba K, Ohuchi A, Saigenji K, Nagura H, Ohtani H: CD8+ T cells infiltrated within cancer cell nests as a prognostic factor in human colorectal cancer. Cancer Res, 58: 3491-3494, 1998.

4. Benhattar J, Delacretaz F, Martin P, Chaubert P, Costa J: Improved polymerase chain reaction detection of clonal Tcell lymphoid neoplasms. Diagn Mol Pathol, 4: 108-112, 1995.

5. Mulder WM, Stukart MJ, de Windt E, Wagstaff J, Scheper RJ, Bloemena E: Mucin-1-related T cell infiltration in colorectal carcinoma. Cancer Immunol Immunother, 42: 351-356, 1996.

6. Dunn GP, Bruce AT, Ikeda H, Old LJ, Schreiber RD: Cancer immunoediting: from immunosurveillance to tumor escape. Nat Immunol, 3: 991-998, 2002.

7. Marrogi AJ, Munshi A, Merogi AJ, Ohadike Y, El-Habashi A, Marrogi OL, Freeman SM: Study of tumor infiltrating lymphocytes and transforming growth factor-beta as prognostic factors in breast carcinoma. Int J Cancer, 74: 492-501, 1997.

8. Nakano O, Sato M, Naito Y, Suzuki K, Orikasa S, Aizawa M, Suzuki Y, Shintaku I, Nagura H, Ohtani H: Proliferative activity of intratumoral CD8(+) T-lymphocytes as a prognostic factor in human renal cell carcinoma: clinicopathologic demonstration of antitumor immunity. Cancer Res, 61: 5132-5136, 2001.

9. Benhattar J, Delacretaz F, Martin P, Chaubert P, Costa J: Improved polymerase chain reaction detection of clonal Tcell lymphoid neoplasm. Diagn Mol Path, 4: 108-112, 1995.

10. Brenner MB, Strominger JL, Krangel MS: The gamma delta T cell receptor. Adv Immunol, 43: 133-192, 1988.

11. Mombaerts P, Arnoldi J, Russ F, Tonegawa S, Kaufmann SH: Different roles of alpha beta and gamma delta T cells in immunity against an intracellular bacterial pathogen. Nature, 365: 53-56, 1993.

12. Girardi M, Oppenheim DE, Steele CR, Lewis JM, Glusac E, Filler R, Hobby P, Sutton B, Tigelaar RE, Hayday AC: Regulation of cutaneous malignancy by gamma delta $\mathrm{T}$ cells. Science, 294: 605-609, 2001.

13. Ikeguchi M, Oi K, Hirooka Y, Kaibara N: CD8+ lymphocyte infiltration and apoptosis in hepatocellular carcinoma. Eur J Surg Oncol, 30: 53-57, 2004.

14. Vesalainen S, Lipponen P, Talja M, Syrjanen K: Histological 
grade, perineural infiltration, tumour-infiltrating lymphocytes and apoptosis as determinants of long-term prognosis in prostatic adenocarcinoma. Eur J Cancer, 30A: 17971803, 1994.

15. Raspollini MR, Castiglione F, Rossi Degl'innocenti D, Amunni G, Villanucci A, Garbini F, Baroni G, Taddei GL: Tumour-infiltrating gamma/delta T-lymphocytes are correlated with a brief disease-free interval in advanced ovarian serous carcinoma. Ann Oncol, 16: 590-596, 2005.

16. Olive C, Nicol D, Falk MC: Characterisation of gamma delta $\mathrm{T}$ cells in renal cell carcinoma patients by polymerase chain reaction analysis of $\mathrm{T}$ cell receptor transcripts. Cancer Immunol Immunother, 44: 27-34, 1997.

17. Spada FM, Grant EP, Peters PJ, Sugita M, Melian A, Leslie DS, Lee HK, van Donselaar E, Hanson DA, Krensky AM, Majdic O, Porcelli SA, Morita CT, Brenner MB: Self-recognition of CD1 by gamma/delta T cells: implications for innate immunity. J Exp Med, 191: 937-948, 2000.

18. Smyth MJ, Trapani JA: Lymphocyte-mediated immunosurveillance of epithelial cancers? Trends Immunol, 22: 409411, 2001.
19. McCarthy KP, Sloane JP, Kabarowski JH, Matutes E, Wiedemann LM: The rapid detection of clonal T-cell proliferations in patients with lymphoid disorders. Am J Pathol, 138: 821-828, 1991.

20. Van Ravenswaay Claasen HH, Kluin PM, Fleuren GJ: Tumor infiltrating cells in human cancer. On the possible role of CD16+ macrophages in antitumor cytotoxicity. Lab Invest, 67: 166-174, 1992.

21. Santin AD, Hermonat PL, Ravaggi A, Bellone S, Roman JJ, Smith CV, Pecorelli S, Radominska-Pandya A, Cannon MJ, Parham GP: Phenotypic and functional analysis of tumorinfiltrating lymphocytes compared with tumor-associated lymphocytes from ascitic fluid and peripheral blood lymphocytes in patients with advanced ovarian cancer. Gynecol Obstet Invest, 51: 254261, 2001.

22. Coulie PG, Karanikas V, Colau D, Lurquin C, Landry C, Marchand M, Dorval T, Brichard V, Boon T: A monoclonal cytolytic T-lymphocyte response observed in a melanoma patient vaccinated with a tumor-specific antigenic peptide encoded by gene MAGE-3. Proc Natl Acad Sci USA, 98: 10290-10295, 2001. 